\section{University-Industry Interaction}

\section{An ACAPPI Report available free of charge from the EPS Secretariat in Geneva}

Following the initiative in 1979 of one of its members who had prepared a report on the efforts made in Sweden to bridge the industry-university gap (Lundqvist D., Europhysics News 11 (1980) 4, 10) the EPS Advisory Committee on Applied Physics and Physics in Industry called for reviews from its members on the situation in their own country with the object of preparing a joint statement and recommendations. These have now been published with the endorsement of the EPS Executive Committee under the title: Improving Interaction between Universities and Industries: Promoting Applications of Physics, an EPS report by Dick Lundqvist (EPS, Geneva) 1983. Copies have already been sent to Council members, the national societies and Associate Members.

Printed on a B5 format and attractively "packaged", the report contains some 20 pages of analysis and evaluation that synthesise the diverse comments that were received. As the introduction states "... measures used varied a great deal from country to country according to the organization of the scientific community and economic system" but there is a commonality of problems and, in general, dissatisfaction with the present state. Industry and university are seen to exist side by side with little reference to each other. This is perhaps less serious for large industries, which have big, well-equipped and wellfunded laboratories, than for small industries which are unable to support $R \&$ \& on their own. Overall, it is found that universities tend to discourage the younger physicists from being interested in the application of their research, and industry tends to remain in ignorance of developments that could mould their future production.

Factors impeding the transfer of new knowledge through to a marketable product are:

- Inertia in the acceptance of new systems;

- Suspicion expressed by opinion formers and politicians;

- Financial problems of supporting R \& D with its inherent risk;

- Long development times between research and final application.

Among the problems discouraging a better interaction are, on the university side:

- Lack of experience in conducting projects on to application;

- Lack of experience in taking cost-efficiency into account;

- Reluctance to accept time constraints or long term commitments;

- Unclear rules governing external cooperation.

On the industry side:

- Inadequate understanding of university conditions:
- Financial demands with no certain return;

- Low priority given to research in management evaluations.

Amongst the general recommendations that are made, are a plea for universities to modify their student training programmes to focus more on applied physics and to set up information secretariats on their research. Industry is urged to recognize the importance of keeping closely in touch with the academic sphere. Personal contacts are vital, and arrangements need to be made for both university teachers as well as trainees to spend time in an industrial environment. Conversely $R \& D$ people in industry should be encouraged to give courses in universities and work there on appropriate subjects.

Governments can do much by channelling funds into joint projects, covering the risks inherent in projects which could be of national importance and establishing collective $R$ \& $D$ institutes in special fields of especial value to the smaller industries. Certain countries have made a success of "Science Parks" which facilitate the creation of spin-off companies from universities, but all governments can make a real contribution by eliminating needless bureaucracy.

EPS too has a role. Within ACAPPI it is proposed to keep the subject under continuous review and to pursue the policy of stimulating meetings on the application of new physics and pressing for a proper representation of applied subjects in major conferences. ACAPPI also proposes to launch a number of case studies to learn of

\section{New Members of EPS}

\section{CATEGORY 4a)}

M. Ibrahim, Sohag, Egypt

C.-E. Morosanu, Bucharest, R

$P$. Paillère, Sceaux, $F$

\section{CATEGORY 4c)}

Austrian Physical Society

J.W. Edenstrasser, Innsbruck

M. Faber, Vienna

C.W. Fabjan, CERN, CH

H. Gruber, Graz

W. Lindinger, Innsbruck

P. Mascher, Graz

E. Schachinger, Graz

F. Schoeberl, Vienna

\section{Danish Physical Society}

U.G. Jørgensen, Copenhagen

Eötvös Lorand Physical Society

L. Cser, Budapest

L. Nanai, Szeged

French Physical Society

J.M. Besson, Paris

S. Bratos, Paris
German Physical Society

M. Abd-Elmeguid, Bochum

G. Brusdeylins, Göttingen

P. Grosse, Aachen

K. Lackner, Garching

L. Merten, Münster-Roxel

W. Trautmann, Upton, USA

Hellenic Physical Society

A. Markou, CERN, $\mathrm{CH}$

Icelandic Physical Society

T.I. Sigfusson, Reykjavik

The Institute of Physics

F. Davey, Clitheroe

A. Peacock, Derby

P. Schofield, Abingdon

Institute "Ruder Boskovic"

G. Paic, Zagreb

Italian Physical Society

C.E. Bottani, Milan

B. Catania, Turin

L. Miglio, Milan

N. Terzi, Milan
The Netherlands' Physical Society

J. van der Klink, Lausanne, $\mathrm{CH}$

J. van Paradijs, Amsterdam

Norwegian Physical Society

J. Lothe, Oslo

Physical Section, Union of Yugoslav Societies of Mathematicians, Physicists and Astronomers

J. Brana, Sarajevo

Polish Physical Society

S. Glazek, Warsaw

B. Sikora, Warsaw

H. Stachowiak, Wroclaw

W. Suski, Wroclaw

Portuguese Physical Society

M. de Carvalho Fernandes Tomaz, Aveiro

M.E.M.F. Pereira, Aveiro

Romanian National Committee for Physics

I.N. Mihailescu, Bucharest

I. Muscutariu, Timisoara

Spanish Royal Society of Physics

A. Giro Roca, Barcelona

Swedish Physical Society

J. Bernhard, Uppsala

Swiss Physical Society

Ch. Rossel, Geneva

D. Schreyer, Lausanne
Turkish Physical Society

H. Ögelman, Ankara

\section{CATEGORY 4d)}

Md. Abdul Mazed, Santa Barbara, USA

F.W. de Wette, Austin, USA

J.-P. Didelez, Orsay, F

E. Fawcett, Toronto, Canada

K. Gentle, Austin, USA

V. Litovchenko, Norman, USA

K.S. Rajput, Bhopal, India

A.L. Rogister, Jülich, D

H.S. Taylor, Los Angeles, USA

A. Wokaun, Zurich, $\mathrm{CH}$

\section{ASSOCIATE MEMBERS}

CISE - Centre for Information,

Studies \& Experiments

POB 12081

1-20134 Milan

ELSAG - Elettronica San Giorgio

Via Hermada 6

POB 125

I-16154 Genova-Sestri

Tungsram

United Incandescent Lamp and

Electrical Company Limited

Vaci ut 77

$\mathrm{H}-1340$ Budapest

Vacuumschmelze GmbH

Grüner Weg 37

D-6450 Hanau 1 
the strengths and weaknesses of university-industry collaborations that are in operation. Interaction with our own Associate Members is to be intensified. The national societies of EPS are urged to exert pressure in their own countries on governments, university authorities and industry to take action along the lines indicated and to treat the subject as both serious and urgent.

Copies of the full report are available, free of charge, on request from the EPS Secretariat in Geneva.

\section{Helping Developing Countries}

The International Centre for Theoretical Physics in Trieste has renewed its appeal for help in supplying libraries of universities in developing countries with back issues of journals and copies of physics books. Previous appeals have produced an encouraging response, but the need is great and continual. Little improvement is to be seen in the funding available for scientific information and frequently inflation and balance of payments' difficulties cause a deterioration in real terms so that the information deficit steadily rises even if a nucleus has, at one time, been established.

Colleagues in the more fortunate countries do not have illimited resources but they are, in the main, able to keep pace with current literature - if they can find somewhere to put it. Many physicists and libraries find their shelves packed with old journals and text books that they cannot bear to throw away, primarily, because they are still in good condition. These are what ICTP would like to direct towards the needy.

There is a similar market for redundant laboratory apparatus. Schools and universities accumulate equipment which has become obsolete because of changes in curricula, changes in teaching style, etc. but which could find a second life if only there were a means of directing it towards those in want.

This exists: For journals, books and apparatus, ICTP has established a coordination centre which will inform potential donors of the acceptability of their offer and the place to which the material concerned should be sent. If you have in physics and mathematics any textbooks you no longer use, volumes of journals that are taking up valuable space, or apparatus that is only gathering dust, write to:

Professor H.R. DALAFI

International Centre for Theoretical Physics POB 586

1-34100 Trieste

giving him details of what you are prepared to donate. He will then explain what should be done.

\section{International Physics}

\section{Impressions of the EPS Symposium on International Facilities for Physics Research}

As a follow-on to the Symposium on European Great Projects held in Rome from 26-27 March 1979, a Symposium on International Facilities for Physics Research was held from 21-23 March 1983 in Copenhagen and Ris $\emptyset$ prior to the meeting of the EPS Council. Sponsored also by the American Physical Society, the Risø National Laboratory (celebrating the 25th anniversary of its foundation through the initiative of Niels Bohr) and the Novo Foundation, and organised by a committee chaired by A.R. Mackintosh, the Symposium aimed at reviewing major facilities (existing and planned) for physics research throughout the world.

\section{Nuclear and Particle Physics}

At the opening session, contrasting pictures were painted of the diffuse situation in nuclear physics and the highly organised state of high energy physics where not only are the physicists mobilised on a regional basis, but even the major regions have complementary rather than competitive programmes. In the $1950 \mathrm{~s}$, much of the fundamental research in nuclear structure was made using Van de Graafs and small cyclotrons in university laboratories; in the ' 60 s tandem accelerators and isochronous cyclotrons came into operation and the inhigh resolution spectroscopy. By the '70s, with the upgrading of tandems and the growth in importance of heavy ion accelerators and electron linacs the centre of gravity had moved into specialised centres and, with the demand for machines of increased intensity and energy, collaboration at the international level is now becoming necessary. This trend is already in evidence. troduction of germanium detectors allowed
Machines that will be required before long include electron accelerators of a few $\mathrm{GeV}$ and high intensity (see Laget J.M. Europhysics News, May 1983), heavy ion accelerators capable of imparting up to 30 $\mathrm{GeV}$ per nucleon, as well as accelerators for the production of high intensity kaon and antiproton beams. Superconducting technology is becoming increasingly important, but the principles of acceleration remain traditional for the present, and novel methods will be required if continued progress is to be made. In comparison with high energy physics projects, the size of machines for nuclear physics research will remain modest, and a form of cooperation in which international use is made of a national facility, would seem to be more appropriate than another CERN.

CERN has now a multiplicity of interconnected accelerators and storage rings capable of a great diversity of operation. The most important facility is the $450 \mathrm{GeV}$ proton machine with an intensity of nearly $3 \times 10^{13}$ protons/pulse. It can be operated as a $270-270 \mathrm{GeV}$ proton-antiproton collider achieving luminosities of $5 \times 10^{28} \mathrm{~cm}^{-2}$ $\mathrm{S}^{-1}$ and the dramatic discoveries of the $\mathrm{W}$ and $Z^{\circ}$ particles provide triumphant proof of its research potential. The $p-p$ Intersecting Storage Rings with a centre of mass energy of $62 \mathrm{GeV}$ and luminosities of up to $1.4 \times 10^{32} \mathrm{~cm}^{-2} \mathrm{~s}^{-1}$ will be closed down at the end of this year to provide resources for the electron-positron ring LEP which will start as a $50-50 \mathrm{GeV}$ machine, then with superconducting RF cavities will be stretched to $80-80 \mathrm{GeV}$ and afterwards to $125-125 \mathrm{GeV}$. At the other end of the energy scale, a wide range of experiments is being conducted on low energy antiproton beams (momentum $0-600 \mathrm{MeV} / \mathrm{c}$ ) of very low momentum spread.
Table 1 - High Energy Physics Facilities Available in the USA

\begin{tabular}{|c|c|c|c|c|c|}
\hline Laboratory & & Device & Energy, GeV & $\begin{array}{l}\text { Intensity/ } \\
\text { Luminosity, } \\
\mathrm{cm}^{-2} \mathrm{~s}^{-1}\end{array}$ & Remarks \\
\hline BNL & AGS & p-synch. & 30 & $10^{13 / 2 \mathrm{~s}}$ & fixed target \\
\hline Fermilab & - & p-synch. & 400 & $2 \times 10^{13 / 10 s}$ & fixed target \\
\hline \multirow[t]{3}{*}{ SLAC } & - & e-linac & 33 & $10^{14} \mathrm{e} / \mathrm{s}$ & $\begin{array}{l}\text { fixed target } \\
\text { primarily e, } \gamma\end{array}$ \\
\hline & SPEAR & $\mathrm{e}^{+}-\mathrm{e}^{-}$collider & $3.5 /$ beam & $1.5 \times 10^{31}$ & ( 2 interaction regions) \\
\hline & PEP & $\mathrm{e}^{+}-\mathrm{e}^{-}$collider & $14.5 /$ beam & $2.2 \times 10^{31}$ & (6 interaction regions) \\
\hline \multirow[t]{2}{*}{ Cornell } & CESR & $\mathrm{e}^{+}-\mathrm{e}^{-}$collider & $5.2 /$ beam & $1.5 \times 10^{31}$ & ( 2 interaction regions) \\
\hline & & & & 500 (nb-day) $^{-1}$ & \\
\hline LANL & LAMPF & $\mathrm{p}$-linac & $0.8 \mathrm{GeV}$ & $10^{15} / \mathrm{s}$ & fixed target \\
\hline
\end{tabular}

